\title{
Taurine determination by capillary electrophoresis with laser-induced fluorescence detection: from clinical field to quality food applications
}

\author{
Angelo Zinellu - Salvatore Sotgia - Bastianina Scanu • \\ Roberto Chessa - Leonardo Gaspa · Flavia Franconi · \\ Luca Deiana · Ciriaco Carru
}

Published online: 13 February 2008

(C) Springer-Verlag 2008

\section{Erratum to: Amino Acids}

DOI 10.1007/s00726-007-0022-5

The name of the third author is Bastianina Scanu. Scanu is the family name.

The authors apologise for the mistake.

The online version of the original article can be found under doi:10.1007/s00726-007-0022-5.

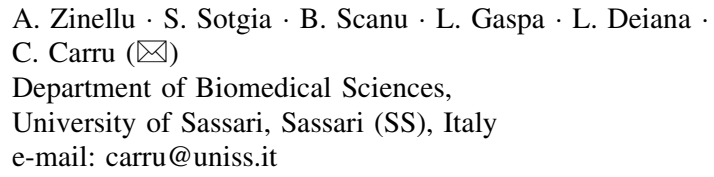

